\title{
Potential immunomodulatory role of VIP in the implantation sites of prediabetic nonobese diabetic mice
}

\author{
Valeria Roca, Mario Calafat, Luciana Larocca, Rosanna Ramhorst, Mariana Farina, \\ Ana Maria Franchi ${ }^{1}$ and Claudia Pérez Leirós \\ Immunopharmacology Laboratory, Department of Biological Chemistry, School of Exact and Biological Sciences, \\ University of Buenos Aires, CONICET, Ciudad Universitaria, Pab. II, 4th Floor, 1428 Buenos Aires, Argentina and \\ ${ }^{1}$ Laboratory of Physiopathology of Pregnancy and Labor, School of Medicine, Center for Pharmacological and \\ Botanical Studies (CEFYBO), University of Buenos Aires, CONICET, Paraguay 2155, 1121 Buenos Aires, Argentina \\ Correspondence should be addressed to C Pérez Leirós; Email: cpleiros@qb.fcen.uba.ar
}

\begin{abstract}
Among several factors known to modulate embryo implantation and survival, uterine quiescence and neovascularization, maternal immunotolerance through the Th1/Th2 cytokine balance towards a Th2 profile, local regulatory T-cell (Treg) activation, and high levels of progesterone were assigned a prominent role. Vasoactive intestinal peptide (VIP) is a neuroimmunopeptide that has anti-inflammatory effects, promotes Th2 cytokines and $\mathrm{CD}^{+}{ }^{+} \mathrm{CD} 25{ }^{+} \mathrm{FOXP}^{+}$Treg activation, and stimulates exocrine secretion, smooth muscle relaxation, and vasodilatation favoring uterus quiescence. The goal of the present work was to explore the participation of VIP in the implantation sites of normal and pregnant prediabetic nonobese diabetic (NOD) females, a mouse strain that spontaneously develops an autoimmune exocrinopathy similar to Sjögren's syndrome. Our results indicate a reduction in litter size from the third parturition onwards in the NOD female lifespan with increased resorption rates. Progesterone systemic levels were significantly decreased in pregnant NOD mice compared with BALB/c mice, although the allogeneic response to progesterone by spleen cells was not impaired. VIP receptors, Vipr1 and Vipr2 (Vpac1 and Vpac2), were expressed at the implantation sites and VIP induced leukemia inhibitory factor (LIF) and Treg marker expression in both strains; however, a reduced Vip expression was found in NOD implantation sites. We conclude that the reduced birth rate at 16-week-old NOD mice with a Th1 systemic cytokine profile involves resorption processes with a lower expression of VIP at the sites of implantation, which acts as a local inducer of pro-implantatory LIF and Treg activation.
\end{abstract}

Reproduction (2009) 138 733-742

\section{Introduction}

During pregnancy, immune and neuroendocrine regulation of the maternal-fetal 'dialogue' is central to both implantation and the development of the placenta. Several factors modulate embryo implantation and survival, thus promoting maternal immunotolerance, uterine quiescence, and neovascularization.

The Th1/Th2 cytokine shift towards a Th2 profile was shown as a favoring factor for fetus survival (Raghupathy 1997, Piccinni et al. 1998, Hanzlikova et al. 2009). In line with this, patients with Th1 autoimmune diseases such as multiple sclerosis and rheumatoid arthritis improve during pregnancy (Nelson \& Ostensen 1997, Cutolo 2000, Olsen \& Kovacs 2002). Also, reports showed that the incidence of fetal loss is not increased in autoimmune patients with rheumatoid arthritis, while a significantly higher frequency of spontaneous abortion was found before the disease onset in a retrospective study of patients with Sjögren's syndrome (Siamopoulou-Mavridou et al. 1988). However, recent reports show that rather than a global Th2 bias, most cytokine production appears to be regulated in the fetomaternal interface during early pregnancy to maintain a relative balance (Halonen et al. 2009).

Among various immunomodulatory factors that participate in the establishment and progression of gestation, progesterone has a prominent role by shifting Th1/Th2 cytokines to a Th2 profile (Szekeres-Bartho 2002). Also, high levels of progesterone prolong the survival of allogeneic skin grafts in hamster uteri (Moriyama \& Sugawa 1972), while stimulation by fetal antigens induces the expression of progesterone receptors (Chiu et al. 1996). Allorecognition of paternal antigens can also increase the production of growth factors and hormones essential for embryonic and fetal development as leukemia inhibitory factor (LIF) among others (Rugeles \& Shearer 2004). Similarly, $\mathrm{CD} 4{ }^{+} \mathrm{CD} 25^{+}$regulatory T-cells (Treg) are known to have an essential role in the induction of maternal tolerance preventing spontaneous abortion (Aluvihare et al. 2004, Saito et al. 2007). 
A decreased number of decidual Treg cells were reported in the mouse model of abortion $\mathrm{CBA} / \mathrm{J} \times \mathrm{DBA} / 2$ (Zenclussen et al. 2005), whereas $\mathrm{CD} 4{ }^{+} \mathrm{CD} 25^{+} \mathrm{T}$ cell increase was stated from days 2 to 3 of gestation independently of the allogeneic or syngeneic nature of pregnancy (Aluvihare et al. 2004). Also, CTLA4lg gene transfer was recently shown to improve pregnancy outcome by expanding the $\mathrm{CD} 4{ }^{+} \mathrm{CD} 25^{+}$Treg population (Li et al. 2009). Finally, LIF has also been involved in graft acceptance and alloantigen-driven tolerance, whereas Tregs release high levels of LIF (Metcalfe et al. 2005, Zenclussen et al. 2006).

Vasoactive intestinal peptide (VIP) mediates a wide variety of nervous, immune, and developmental functions. As a neuropeptide of the peripheral nervous system, it stimulates exocrine secretion and vasodilatation (Ekström et al. 1983, Inoue et al. 1985). Interestingly, VIP contributes to smooth muscle relaxation and vasodilatation favoring uterus quiescence (Clark et al. 1981, Jovanovic et al. 1998). As an immunopeptide, it promotes anti-inflammatory and Th2 cytokine responses in various models of inflammatory response and autoimmune disease (Gonzalez Rey \& Delgado 2007, Leceta et al. 2007). VIP has also been proposed as an inducer of $\mathrm{CD} 4{ }^{+} \mathrm{CD} 25^{+} \mathrm{FOXP} 3^{+}$ Tregs, helping to maintain immunotolerance in different animal models including nonobese diabetic (NOD) mice (Rosignoli et al. 2006, Gonzalez Rey \& Delgado 2007). Finally, VIP participates in the maternal regulation of embryonic growth in rodents during the early post-implantation period and the blockade of VIP function induced growth retardation and microcephaly (Gressens et al. 1994, Spong et al. 1999, Rangon et al. 2006).

The NOD mouse model of Sjögren's syndrome is an invaluable tool to study the outcome of pregnancy before the onset and during the autoimmune response. NOD mice at the prediabetic stage spontaneously develop an autoimmune exocrinopathy with a systemic Th1 cytokine response resembling Sjögren's syndrome. A deep exocrine dysfunction precedes a mild mononuclear infiltration of the glands, which can be partly explained by multiple immune-regulatory defects (Anderson \& Bluestone 2005, Piccirillo et al. 2005, Rosignoli et al. 2005). Among these defects, NOD mice present a lower number of Tregs, although they retain their suppressive capacity since depletion accelerates the progression of the autoimmune response (Pop et al. 2005). Regarding reproductive tissues, we have previously reported a decreased response to VIP in the uterus of normally cycling 16-week-old prediabetic NOD mice, simultaneously to the increase of Th1 cytokines in serum (Roca et al. 2006).

The goal of the present work was to monitor the reproductive score of prediabetic NOD females focusing on the potential regulation by VIP of local modulatory factors at the implantation sites. We provide evidence of a reduced birth rate from the third litter onwards at 16 weeks of age, which is associated with increased resorption processes, decreased serum progesterone, and decreased expression of VIP at the sites of implantation, which acts locally as an inducer of proimplantatory factors, LIF and Treg-activated cells.

\section{Results \\ Litter size in NOD mice lifespan and embryonic resorption profile}

Figure $1 \mathrm{~A}$ shows a significant decline in the litter size of NOD mice from the third parturition onwards. It is worth noting that the first reduction in litter size is around the 18th week of mothers' age. These females had been mated at 16 weeks of age coinciding with the onset of the systemic Th1 cytokine response previously described in these mice (Roca et al. 2006). A more profound failure in reproductive score is registered at the diabetic stage that occurs about the 30th week in our breeding conditions. Control BALB/C mice litter sizes (Fig. 1B) show that there is no decline up to the fourth gestation and even not further (28 weeks of age, data not shown). To investigate whether this decline in offspring at the third gestation was an effect of multiple gestations or it also occurred at the first pregnancy, we mated virgin NOD females of 16 weeks of age and obtained similar results (NOD mice born/mother, mean \pm S.E.M. $=5.0$ \pm 0.8 . Also, since diabetes is known to impair pregnancy in this strain, we measured glucose serum levels in pregnant 16-week-old NOD mice, either in their first gestation or in the third one. Glucose levels did not differ either between NOD mice or compared with normal BALB/C pregnant mice (Table 1). In order to explore whether an implantation failure or a resorption process underlies this lower offspring score, we mated 16-week-old female NOD mice (first mating) with male NOD mice. On the 9th day after the vaginal plug was seen, female mice were killed, post-implantation embryos were counted and separated for histological

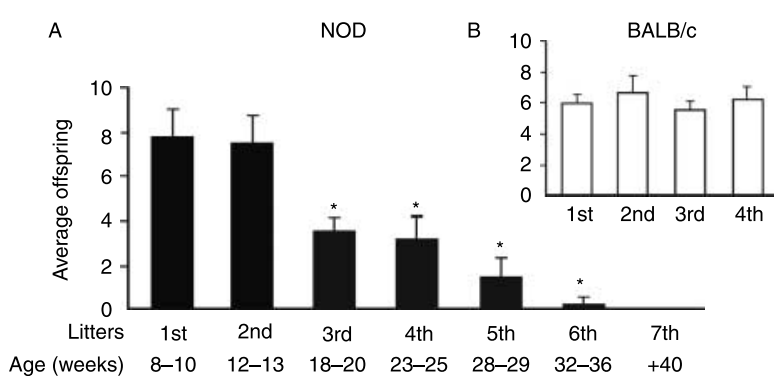

Figure 1 Reduced litter size in NOD mice. NOD (A) and BALB/C (B) mice were syngeneically mated during lifespan beginning at 8 weeks, and offspring was recorded as well as the mother's age at the time of parturition. Values represented are the mean \pm S.E.M. of 20 females. $* P<0.05$ versus NOD first litter. 
Table 1 Glucose levels in 16-week-old pregnant nonobese diabetic (NOD) mice.

\begin{tabular}{llcc}
\hline & $\begin{array}{c}\text { NOD first } \\
\text { gestation }\end{array}$ & $\begin{array}{c}\text { NOD third } \\
\text { gestation }\end{array}$ & BALB/c \\
\hline Glucose $(\mathrm{g} / \mathrm{l})$ & $0.8 \pm 0.2$ & $0.75 \pm 0.1$ & $1.0 \pm 0.1$
\end{tabular}

Freshly isolated serum from each pregnant animal, either NOD or $\mathrm{BALB} / \mathrm{C}$, was individually processed and glucose levels were determined as described in Materials and Methods. Values are the mean \pm s.E.M. of six separate determinations.

studies. As it can be seen in Fig. 2A, healthy embryos were macroscopically different from those in the process of resorption. Histological studies revealed a conserved muscular layer, infiltrating immune cells in the decidualized tissue (a) and hemorrhages (b). In the lower panel, an incipient infiltration of aligned mononuclear cells can be seen as well as decidual cells detaching from the villi (c). The rate of resorbed embryos versus total embryos was $32 \%$ (60 resorbed/187 evaluated) (Fig. 2B), higher than the normal rate reported for control mouse strains (Zenclussen et al. 2006). Similar resorption rates were obtained in mothers NOD at third gestation (not shown).

\section{Serum levels of progesterone and estradiol and systemic alloreactivity}

Since progesterone and estradiol play key roles in the physiology of reproduction, we measured their levels in the serum of pregnant NOD and BALB/c mice. Compared with BALB/c mice, significantly lower progesterone levels were found in pregnant NOD mice serum even if they had no signs of embryo resorption (Fig. 3A). In fact, progesterone levels were even lower in
NOD mice with more than four resorption sites. However, no differences were seen in the estradiol levels in pregnant NOD mice compared with NOD mice with more than four resorption sites or with $\mathrm{BALB} / \mathrm{c}$ mice (Fig. 3A, left panel). On the hypothesis that an exacerbated splenocyte alloresponse not properly regulated by progesterone might have a role in the increased resorption rate, we measured the maternal immune response to paternal antigens by splenocytes in pregnant NOD and BALB/C mice at day 9 of gestation. When taking into consideration the proliferation rate, no significant difference was found between the two strains. Also, progesterone was able to inhibit the response to the same extent in both mice strains, suggesting that although progesterone levels are diminished in NOD mice, spleen cells present a similar response to paternal antigens and progesterone regulation compared with normal mice cells (Fig. 3B).

\section{Vip and VIP receptors expression}

VIP has smooth muscle relaxation effects and induces proTh2-proTreg profiles consistent with the maintenance of uterine quiescence and immuno-tolerogenic mechanisms, on one hand, and it has also been involved in fetal growth, on the other hand. Thus, we investigated the expression levels of Vip mRNA and VIP receptors mRNA, Vipr1 and Vipr2 (also known as Vpac1 and Vpac2), in NOD and BALB/c implantation sites. As shown in Fig. 4A, there was a decrease in Vip mRNA levels at the implantation sites of NOD mice compared with BALB/c mice. NOD mice with more than four resorption sites were also tested for Vip expression, and the levels were significantly reduced compared with NOD mice with normal embryos. To quantify Vip mRNA
A

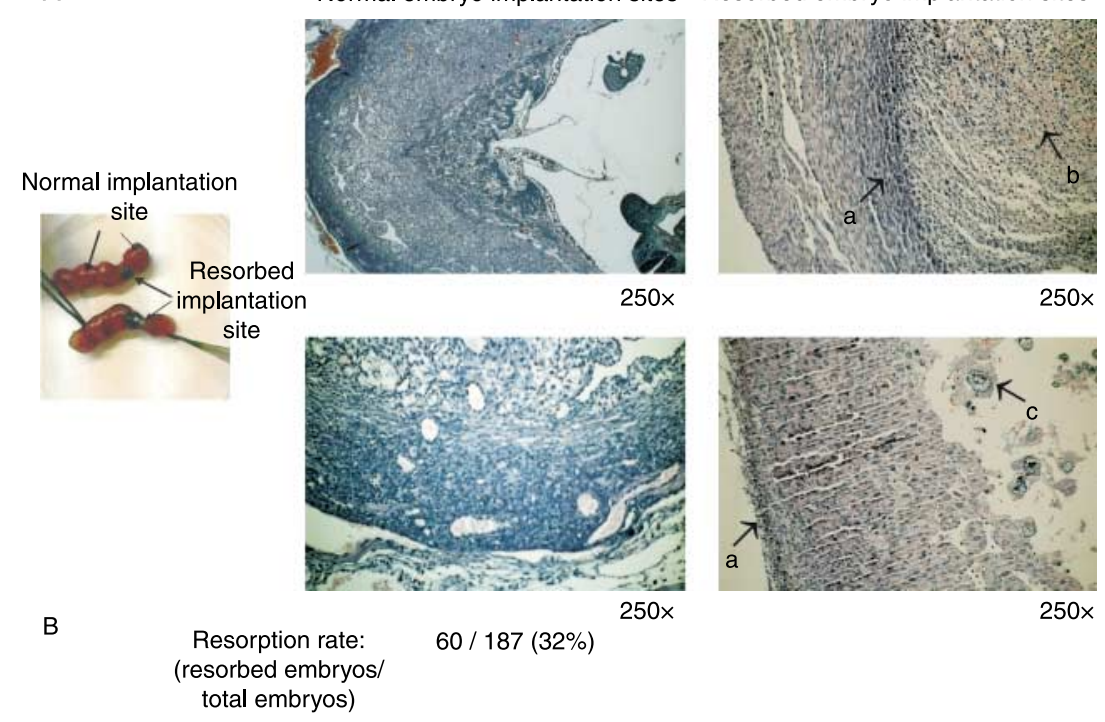

Figure 2 Increased resorption rate in prediabetic NOD mice. (A) Uteri from pregnant NOD mice were processed for histological studies and hematoxylin-eosin staining. Sections shown are representative of four other slices analyzed similarly, $250 \times$. The arrows indicate: (a) mononuclear infiltrates; (b) hemorrhages; (c) detached cells. (B) Resorption rate was calculated as the number of resorbed embryos over total embryos counted. 

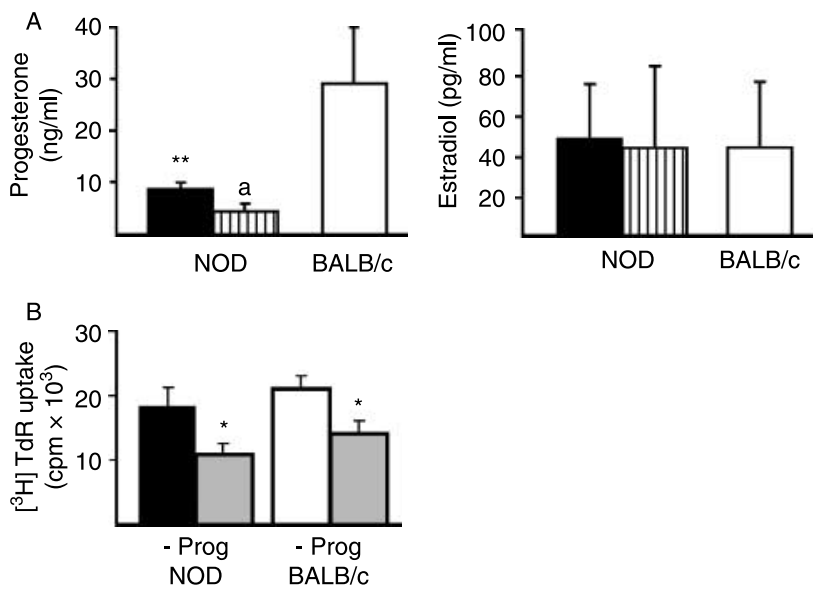

Figure 3 Decreased progesterone serum levels. (A) Freshly isolated serum from each animal, NOD mice with healthy implantation sites (NS, black bars), NOD mice showing sites with signs of resorption (RS, striped bars), and BALB/C mice (empty bars) were individually processed, and progesterone and estradiol levels were determined by RIA as described in Materials and Methods. Values are the mean \pm s.E.M. of six separate animals. ${ }^{* *} P<0.01$ versus BALB/c. ${ }^{a} P<0.05$ versus NOD NS. (B) Single-cell suspensions were prepared from pregnant NOD and BALB/C mice spleens and co-cultured with male C57BL/6J splenocytes, previously treated with mitomycin $C(0.5 \mathrm{ng} / \mathrm{ml})$ in the presence or absence of progesterone $\left(10^{-5} \mathrm{M}\right)$. After $72 \mathrm{~h}$, cells were pulsed with $1 \mu \mathrm{Ci} /$ well of methyl- $\left[{ }^{3} \mathrm{H}\right]$-thymidine $\left[{ }^{3} \mathrm{H}\right] \mathrm{TdR}$ and then harvested. Tests were conducted in triplicate, and results were expressed as mean c.p.m. \pm s.E.M. ${ }^{*} P<0.05$ versus basal.

expression, real-time RT-PCR was performed and the above results were further confirmed (Fig. 4B). In contrast, there were no detectable differences in mRNA levels of Vipr1 or Vipr2 between normal NOD and BALB/c implantation sites (Fig. 4C).

\section{Effect of VIP on pro-implantatory factors}

Since VIP has been associated with induction of Tregs and we have described a lower response to VIP in uteri of nonpregnant female NOD mice, we investigated the functionality of VIP receptors by exploring the ability of exogenous VIP to induce LIF expression and FOXP3 major differentiation marker of $\mathrm{CD} 4{ }^{+} \mathrm{CD} 25^{+}$Treg in the implantation sites. Hence, explants of healthy implantation sites from NOD and BALB/c mice were cultured for $24 \mathrm{~h}$ in the presence or absence of $100 \mathrm{nM} \mathrm{VIP}$, and the expression of FOXP3 and LIF was assessed by western blot. We observed that VIP significantly increased FOXP3 and LIF expression in implantation sites from NOD and BALB/C mice (Fig. 5A). To further analyze the effect of VIP on Treg population, we performed triple staining protocols to identify Treg population (CD4 FITC, CD25 APC, and FOXP3 PE) in $\mathrm{NOD}$ and $\mathrm{BALB} / \mathrm{C}$ mice healthy implantation sites. Figure 5B shows a representative dot plot for NOD and $\mathrm{BALB} / \mathrm{C}$ mice in basal and VIP-stimulated conditions.
No detectable differences in the frequency of Tregs in basal conditions were seen between NOD and BALB/C mice, and also, VIP slightly increased the frequency of this population to the same extent in both mice strains.

\section{Discussion}

Pregnancy is a tightly regulated process, where systemic and local mechanisms act in synchronicity to allow the maternal immune system to tolerate the fetus. A unique situation takes place when autoimmunity underlies the course of pregnancy. Certainly, the outcome of pregnancy may be affected by the autoimmune context and,

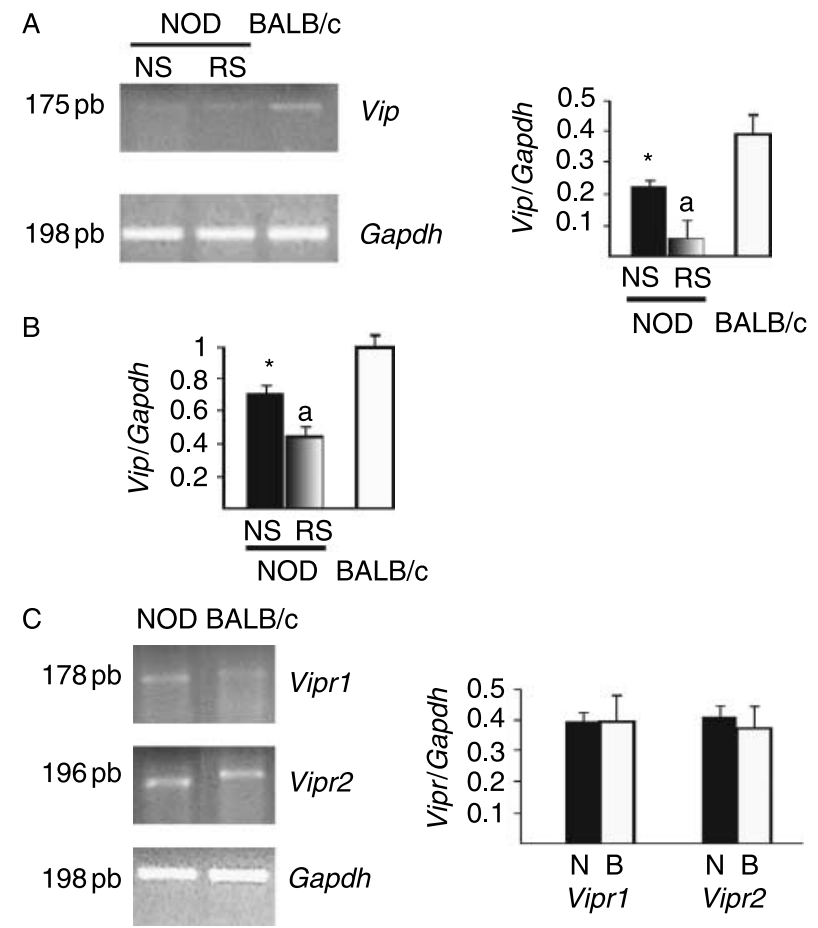

Figure 4 Decreased Vip mRNA levels in normal implantation sites of NOD mice. (A) Vip mRNA expression was evaluated by RT-PCR from normal implantation sites (NS, black bars) of NOD mice, NOD sites with signs of resorption (RS, gray bars), and normal sites of BALB/C mice (empty bars) as described in Materials and Methods. Agarose gels shown are representative of three others. Values indicate the mean intensity relative to Gapdh of each band in arbitrary units (AU) and represent the mean \pm S.E.M. for three separate experiments. ${ }^{*} P<0.05$ versus BALB/c. ${ }^{\mathrm{a}} P<0.05$ versus NOD NS. (B) Vip mRNA expression was quantified by real-time RT-PCR from NOD mice normal sites (NS, black bars), NOD mice sites with signs of resorption (RS, gray bars), and BALB/c mice normal sites (empty bars) as described in Materials and Methods. Values indicate the mean intensity relative to Gapdh of each test in arbitrary units (AU) and represent the mean \pm S.E.M. for three separate experiments. ${ }^{*} P<0.05$ versus BALB/C. ${ }^{a} P<0.05$ versus NOD NS. (C) Vipr1 and Vipr2 mRNA expression was evaluated by RT-PCR from normal implantation sites of NOD mice (black bars) and BALB/C mice (empty bars) as described in Materials and Methods. Agarose gels shown are representative of three others. Values indicate the mean intensity relative to Gapdh of each band in arbitrary units (AU) and represent the mean \pm s.E.M. for three separate experiments. 
A

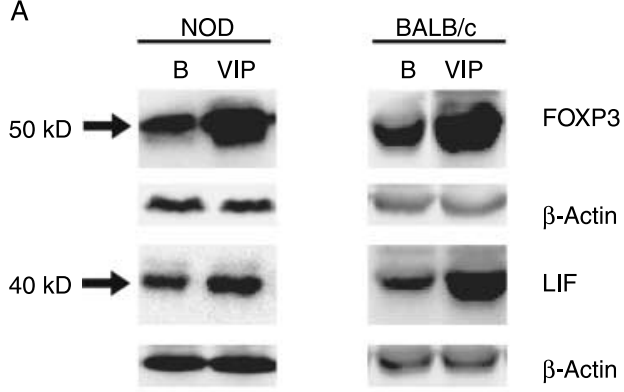

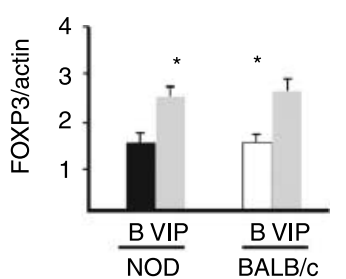

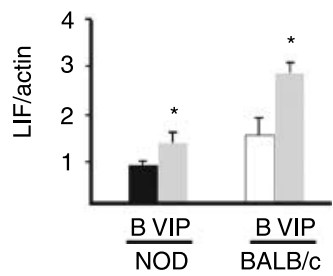

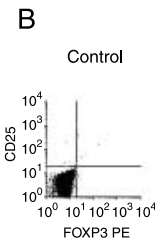

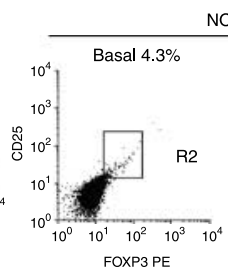

NOD

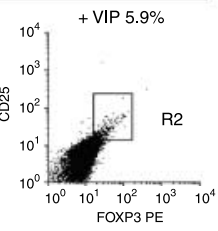

$B A L B / c$
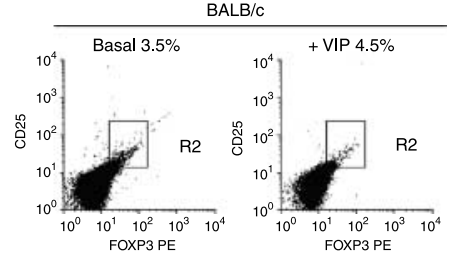

Figure 5 Effect of VIP on pro-implantatory factors. The effect of VIP on the expression of FOXP3 and LIF in normal implantation sites of NOD and BALB/c mice was assessed by immunoblotting, after a $24 \mathrm{~h}$ culture in the presence or absence of VIP $\left(10^{-7} \mathrm{M}\right)$ as described in Materials and Methods. (A) Blots shown are representative of five others. Bars on the right side indicate the mean intensity relative to $\beta$-actin expression of each band in arbitrary units and represent the mean \pm S.E.M. of five blots. B: basal values, VIP-treated (gray bars), ${ }^{*} P<0.05$ versus basal. (B) VIP effect on Tregs frequency was assessed in viable implantation sites from NOD and BALB/C mice by FACS analysis as described in Materials and Methods. Dot plots presented are representative of two other experiments run similarly. while pregnancy was shown to ameliorate various autoimmune diseases, it can also worsen the outcome of others (Waldorf \& Nelson 2008). Therefore, a more deep insight into the mechanisms of maternal-fetal interaction in normal and autoimmune conditions might help to improve the current/available treatments. Several reports describe the effect of established autoimmune disease on pregnancy and its effect on disease; nevertheless, few retrospective reports focused on the outcome of pregnancy before the clinical manifestations of an autoimmune disease. This situation was analyzed in Sjögren's disease, more frequently diagnosed in older women, and a higher frequency of recurrent spontaneous abortions was reported (Siamopoulou-Mavridou et al. 1988).

The aim of the present work was to analyze the reproductive score of prediabetic NOD females as a model of Sjögren's syndrome focusing on the potential role of VIP as a local immunomodulatory factor at the implantation sites. Our results indicate a decline of birth rate in NOD mice paralleling the development of the systemic Th1 cytokine response, with increased resorption rates, decreased systemic progesterone, and decreased expression of VIP at the sites of implantation. VIP appears to act locally as an inducer of proimplantatory factors, LIF and Treg-activated cells. These conclusions are supported by the following evidences presented: first, a reduction in litter size was recorded from the third parturition onwards, only in NOD mice. This occurred at an age of the mother when Th1 cytokines such as tumour necrosis factor- $\alpha$ (TNF) are increasing their serum. Secondly, progesterone systemic levels are significantly decreased in pregnant NOD mice compared with BALB/c mice, although the response to progesterone by spleen cells is not impaired. Thirdly, a significant reduction in Vip mRNA levels was found locally in NOD implantation sites with normal expression of VIP receptors, Vipr1 and Vipr2. These receptors are responsive to exogenous VIP as it was able to increase the expression of two pro-implantatory markers, FOXP3 and LIF, in healthy implantation sites and to increase the frequency of Treg population.

The decrease in offspring around the 16-18th week of age parallels not only the onset of the systemic Th1 cytokine response (Roca et al. 2006) but also the decline in salivary flow rate characteristic of Sjögren's syndromelike stage in NOD mice, and it also clearly precedes the hyperglycemia of the type 1 diabetic stage in NOD mice (Rosignoli et al. 2005), since 16-week-old pregnant NOD mice are normoglycemic. In addition, we found that the resorption rate in this syngeneic pregnancy model was significantly higher than the $3-10 \%$ resorption rate reported for allogeneic and syngeneic pregnancies in control mouse strains. NOD resorption rates shown here are similar to allogeneic pregnancy in NOD/ C57BL/6 of comparable age (Formby et al. 1987, Lin et al. 2008) and comparable with the resorption rates reported for the immunologic abortive model $\mathrm{CBA} / 2 \times$ DBA/J (Zenclussen et al. 2006).

Embryonic resorption has been associated with systemic responses such as a Th1 cytokine profile (Chaouat et al. 1990) and low progesterone levels (Elson \& Jurkovic 2004). At the local level, unusually high levels of nitric oxide synthesis are responsible of 
resorption in an acute inflammation model in mice (Ogando et al. 2003, Aisemberg et al. 2007). Similarly, a low number of Tregs at implantation sites parallel resorption in the abortive mouse model (Aluvihare et al. 2004, Zenclussen et al. 2006). As we showed here, progesterone levels were decreased in the sera of pregnant NOD mice, and this reduction was even greater when resorbed embryos were counted at day 9 of gestation. Progesterone plays a key role in the regulation of gestation due to endocrine as well as immunological effects. Progesterone was found necessary for NK cells homing to the uterus-mediating angiogenesis and neovascularization in human pregnancy (Ancelin et al. 2002). In line with this, we can speculate that a reduction in progesterone serum levels could in turn impair NK cells homing to the uterus. Interestingly, a lower uterine NK cell number was observed in the decidua basalis of diabetic NOD mice females, along with reduced expression of vascular cell adhesion molecule- 1 and aberrant expression of mucosal vascular addressin cell adhesion molecule (MAdCAM)-1 in deciduas (Burke et al. 2007). In the pregnant NOD mouse model of Sjögren's syndrome, we have recently shown that macrophages from mothers at 16 weeks of age and at day 9 of gestation present a lower basal production of IL12 and nitric oxide than macrophages of age-matched nonpregnant NOD mice (Larocca et al. 2008). Moreover, this 'silenced' condition of pregnant NOD macrophages could be partly mimicked in nonpregnant NOD macrophages by incubating cells with progesterone. This result suggests that progesterone or progesterone/estradiol ratio, among other hormonal changes during gestation, is responsible for the antiinflammatory macrophage profile. Interestingly, no significant differences were seen in estradiol serum levels in pregnant NOD mice, either with or without signs of resorption. Thus, in addition to the reduced progesterone levels, the relative ratio of progesterone/ estradiol is also decreased. Regarding Sjögren's syndrome patients, no significant differences were observed in the levels of estrogens and progesterone in sera between patients and controls, although a higher estrogen/progesterone relative ratio was reported (Taiym et al. 2004). It is worth noting that not only the appropriate levels of circulating hormones can influence the progression of gestation but also the expression and signaling through their receptors. To further analyze this, we explored the allogeneic response of maternal splenocytes to paternal antigens and the inhibitory effect of progesterone. Although progesterone levels were reduced in pregnant NOD mice, the allogeneic response was similar in NOD and control mice. Moreover, progesterone added to the cultures inhibited the response to the same extent in both cultures confirming that progesterone receptors and signaling seem appropriate.
Regarding locally acting homeostatic signals, we have previously reported a reduced nitric oxide and increased prostaglandin $E_{2}$ synthesis in the uterus of NOD mice with a concomitant development of a Th1 cytokine profile (Roca et al. 2006). Both signals are known to impair the progression of gestation. Also, other authors have reported on aberrant endometrial features in diabetic pregnant NOD mice, where vascular defects (limited spiral artery development) due to a decreased NK cell's activity resulted in increased murine fetal loss (Burke et al. 2007).

On the knowledge that VIP has anti-inflammatory effects and promotes Th2/Treg profiles in several models of Th1 disease, while it showed an embryotrophic effect at days 9-12 of gestation in rodents, we investigated the presence of VIP in the implantation sites. Local expression of Vip mRNA was assessed at the implantation sites of NOD mice, although at lower levels compared with control mice. VIP receptors Vipr1 and Vipr2 were also expressed at the maternal-embryonic interface suggesting that VIP could specifically act by a local/paracrine mechanism. The level of receptor expression was similar for both subtypes and for control and NOD healthy sites. Also, functionality of VIP receptors locally expressed was assessed by the addition of exogenous VIP to the culture media, which induced a significant increase in FOXP3 and LIF expression and a trend to increase Tregs frequency. In rodent models of embryo implantation and growth, VIP levels increase in the deciduas at the early post-implantation phases, and it has been assigned a role as a neural growth factor for the embryos (Gressens et al. 1998, Spong et al. 1999). Moreover, a reduction in the levels of VIP could lead to growth retardation and microcephaly (Gressens et al. 1994). We have recently reported on the expression of VIP and VIPR1 in a human trophoblast cell line (Fraccaroli et al. 2009). By means of an experimental approach to the human fetal-maternal interface, we showed the participation of endogenous VIP in the fetalmaternal interaction with a pro-implantatory role by increasing the expression of Treg markers and LIF (Fraccaroli et al. 2009). Other authors have reported on the ability of VIP to modulate hCG and progesterone in human trophoblast cultures (Marzioni et al. 2005) and to be selectively concentrated in the uterine vasculature, where its levels have been reported to be 2.5 -fold greater than in maternal blood (Ottesen et al. 1982).

Finally, VIP has been recently proposed as an inducer of $\mathrm{CD} 4{ }^{+} \mathrm{CD} 25^{+} \mathrm{FOXP} 3{ }^{+}$Treg in vivo in the prediabetic NOD mice model (Rosignoli et al. 2006).

During pregnancy, a systemic expansion of $\mathrm{CD} 25^{+}$ Tregs has been shown and the lack of this subset leads to gestation failure (Aluvihare et al. 2004, Zenclussen et al. 2006, Saito et al. 2007). A lower level of systemic Tregs was reported in diabetic NOD mice (Pop et al. 2005); however, a role for these cells in NOD pregnancy yet has not been clarified. 
The reduced expression of VIP at the sites of implantation of NOD mice confirms and extends the observations on the potential pro-implantatory role of VIP in the human maternal-fetal dialogue recently reported by means of an in vitro approach (Fraccaroli et al. 2009). Further studies are needed to address the mechanisms underlying the potential role of VIP as a modulatory factor and the perspectives for its application to therapy of pregnancy failures.

\section{Materials and Methods}

\section{Animals}

NOD and BALB/C females and C57BL/6] males were bred and maintained at the Central Animal Care facility of the School of Exact and Natural Sciences, University of Buenos Aires. They were maintained on a $12 \mathrm{~h}$ light: $12 \mathrm{~h}$ darkness schedule. Each mouse was considered mature at the age of 9-10 weeks. Normally, cycling NOD and BALB/c mice were mated, and day 0 was taken as the day when the vaginal plug was seen. Mice were fasted overnight with water ad libitum before killing; tissues and blood were obtained and processed immediately after. Mice were routinely tested for blood glucose levels (Wiener Lab., Rosario, Argentina) and considered prediabetic as their values of serum glucose on two occasions over a 24-h period did not significantly differ from those of control mice $(1.0 \pm 0.1 \mathrm{~g} / \mathrm{l}, n=27)$. In our breeding conditions, NOD mice diabetes onset is around the 30th week of age, and none of the pregnant animals used throughout were diabetic. Also, confirming previous reports (Roca et al. 2006), NOD mice sera were also assayed for TNF levels showing a significant increase in this cytokine at 16-week-old NOD mice before mating compared with age-matched control mice $(T N F ~ p g / m l$, NOD $230 \pm 11 *, B A L B / C 100 \pm 5 ; * P<0.05$ versus $B A L B / c$, $n=7$ ). All studies were conducted according to standard protocols of the Animal Care and Use Committee of the School of Exact and Natural Sciences, University of Buenos Aires.

\section{Immunohistochemistry}

Uteri from NOD and BALB/C mice were fixed in $4 \%$ paraformaldehyde overnight at $4{ }^{\circ} \mathrm{C}$. The tissues were embedded in paraffin wax, and sections of $4 \mu \mathrm{m}$ were cut and placed on silanized glass slides. Hematoxylin-eosin staining was performed as described elsewhere (Roca et al. 2004).

\section{Progesterone determination}

Progesterone was quantified by specific RIA using rabbit antiserum (Sigma Chemical Co). Briefly, progesterone was extracted from sera with ethyl ether and repeated freeze/thaw cycles (Abraham et al. 1971). The organic phase was dried in vacuum, resuspended in RIA buffer, and measured immediately. Tests were conducted in duplicate, and results were expressed as mean \pm S.E.M $(\mathrm{ng} / \mathrm{ml})$.

\section{Estradiol determination}

Estradiol was quantified by specific Coat-a-Count Estradiol RIA (Siemmens, Los Angeles, CA, USA) according to the manufacturer's instructions. Briefly, the serum samples and the calibrators were incubated with ${ }^{125} \mathrm{I}$-labeled estradiol in the antibody-coated tubes provided by the manufacturer for $3 \mathrm{~h}$ at room temperature. After decantation, the tubes were measured immediately. Tests were conducted in duplicate, and results were expressed as mean \pm s.E.M $(\mathrm{ng} / \mathrm{ml})$.

\section{Allogeneic stimulation}

Spleens from pregnant NOD and BALB/C mice and from C57BL/6J male were removed aseptically, and single-cell suspensions were prepared.

$\mathrm{NOD}$ and $\mathrm{BALB} / \mathrm{c}$ splenic cells (responder cells) were resuspended in complete RPMI $1640\left(1 \times 10^{5}\right.$ cells/well). Male C57BL/6J splenocytes resuspended in complete RPMI $1640\left(1 \times 10^{5}\right.$ cells/well $)$ were treated with mitomycin $\mathrm{C}$ (0.5 ng/ml, Sigma) during $30 \mathrm{~min}$ at $37^{\circ} \mathrm{C}$ to inhibit paternal DNA synthesis (stimulator cells). The mixture of responder and stimulator cells was incubated in a U-shaped microtiter plate (Corning Glass, Corning, NY, USA) at $37^{\circ} \mathrm{C}$ in a humidified atmosphere of $5 \% \mathrm{CO}_{2}$ in the presence or absence of progesterone $\left(10^{-5} \mathrm{M}\right.$, Sigma).

After $72 \mathrm{~h}$, cells were pulsed with $1 \mu \mathrm{Ci} /$ well of methyl- $\left[{ }^{3} \mathrm{H}\right]-$ thymidine $\left[{ }^{3} \mathrm{H}\right] \mathrm{TdR}$ (NEN, Boston, MA, USA) during the last $18 \mathrm{~h}$ of cell culture and then harvested on glass fiber filters using a Packard Filtermate cell harvester (Packard Instruments, LaGrange, IL, USA). Incorporated radioactivity was measured in a liquid scintillation $\beta$-counter (Packard Instruments). Tests were conducted in triplicate, and results were expressed as mean c.p.m. \pm s.E.M.

\section{Immunoblotting detection of FOXP3 and LIF}

Implantation sites' explants were excised out, washed twice, and incubated for $24 \mathrm{~h}$ at $37^{\circ} \mathrm{C}$ in RPMI 1640 medium supplemented with $10 \%$ FCS (Life Technologies) in the presence or absence of VIP $\left(10^{-7} \mathrm{M}\right.$; Neosystem, Strasbourg, France). After incubation, explants were homogenized at $4{ }^{\circ} \mathrm{C}$ in $50 \mathrm{mM}$ Tris- $\mathrm{HCl}$ buffer $\mathrm{pH} 7.5$ with $0.15 \%$ Triton X-100 and protease inhibitors as previously reported for exocrine tissues and uterus (Rosignoli \& Perez Leiros 2002, Roca et al. 2006). Once centrifuged at $5000 \mathrm{~g}$ for $10 \mathrm{~min}$ at $4{ }^{\circ} \mathrm{C}$, supernatants were frozen at $-80{ }^{\circ} \mathrm{C}$ until used, and an aliquot of each sample was separated for protein determination. Extracts (50-100 $\mu \mathrm{g}$ protein/lane), positive controls and molecular weight standards (Amersham Pharmacia Biotech Inc.) were subjected to $10 \%$ or $15 \%$ SDS-PAGE for FOXP3 (MW: 50 kDa, Clone: FJK-16s; eBioscience, San Diego, CA, USA) and LIF (MW: $40 \mathrm{kDa}$, Clone: 9824.11; R\&D, Minneapolis, MN, USA) respectively, transferred to nitrocellulose membranes (Amersham Pharmacia Biotech Inc.), and revealed with ECL substrate reagent (Pierce Biotechnology, Woburn, MA, USA). The immunoreactive protein bands were analyzed with a Fotodyne Image Analyzer (Fotodyne, Inc., Hartland, WI, USA). Results were expressed 
as relative densitometric values by means of the ImageQuant software (GE Healthcare, Chalfont St Giles, UK) relative to $\beta$-actin expression.

\section{Flow cytometry analysis}

Treg were identified using the Mouse Regulatory T cell Staining Kit (PE FOXP3 clone: FJK-16s, FITC CD4 clone: RM4-5, APC CD25 clone: PC61.5, eBioscience) according to the manufacturer's protocol. Implantation sites explants were excised out, washed twice, and incubated for $24 \mathrm{~h}$ at $37^{\circ} \mathrm{C}$ in RPMI 1640 medium supplemented with $10 \%$ FCS (Life Technologies) in the presence or absence of VIP $\left(10^{-7} \mathrm{M}\right.$, Neosystem). After incubation, explants were mechanically disrupted with a tissue homogenizer, and cellular suspension was centrifuged at $2000 \mathrm{~g}$ for $5 \mathrm{~min}$ at $4{ }^{\circ} \mathrm{C}$ and pellets were resuspended. The prepared cells were stained for surface molecules CD4 FITC $(0.125 \mu \mathrm{g} /$ test $)$ and CD25 APC $(0.06 \mu \mathrm{g} /$ test $)$ in $100 \mu \mathrm{l}$ staining buffer. The tests were incubated for $30 \mathrm{~min}$ at $4{ }^{\circ} \mathrm{C}$, and then washed twice ( $2 \mathrm{ml}$ staining buffer), centrifuged at $2000 \mathrm{~g}$ for $5 \mathrm{~min}$ at $4{ }^{\circ} \mathrm{C}$, and decanted. Pellet was resuspended with $1 \mathrm{ml}$ Fix/Perm buffer and incubated for $30 \mathrm{~min}$ at $4{ }^{\circ} \mathrm{C}$ in the dark. After washing twice $(2 \mathrm{ml}$ Perm buffer) and centrifuged at $2000 \mathrm{~g}$ for $5 \mathrm{~min}$ at $4{ }^{\circ} \mathrm{C}$, supernatants were decanted. Intracellular staining for FOXP3 was assessed using FOXP3 PE antibody $(0.5 \mu \mathrm{g} /$ test $)$ in $100 \mu \mathrm{l}$ Perm buffer and incubated for $30 \mathrm{~min}$ at $4{ }^{\circ} \mathrm{C}$ in the dark. After washing twice $(2 \mathrm{ml}$ Perm buffer) and centrifuged at $2000 \mathrm{~g}$ for $5 \mathrm{~min}$ at $4{ }^{\circ} \mathrm{C}$, supernatants were decanted and pellets were resuspended in Flow Cytometry Staining Buffer for analysis. A total of 100000 events were acquired in a FACSCalibur cytometer, and results were analyzed using the WinMDI software (http://facs.scripps. edu/software.html). Negative control samples were incubated in parallel with an irrelevant, isotype-matched antibody. Results for $\mathrm{CD}_{2} 5^{+} \mathrm{FOXP}^{+}$cells are inside the electronical gate performed by CD4-positive staining and on viable cell population, to avoid nonspecific uptake of Abs by dead cells.

\section{RT-PCR for Vip and VIP receptors detection}

Total RNA isolation and RT were performed using TRIzol (Invitrogen) and Ready-To-Go T-Primed First-Strand Kit (Amersham Pharmacia Biotech Inc.) as previously described (Rosignoli et al. 2004). The cDNA was then amplified using the specific primers for Vip, Vipr1, Vipr2, and Gapdh as an internal control. Primers are described in Table 2, and PCR conditions are as follows: for VIP, $95^{\circ} \mathrm{C}$ for $10 \mathrm{~min}, 31$ cycles of $96^{\circ} \mathrm{C}$ for $45 \mathrm{~s}, 57^{\circ} \mathrm{C}$ for $45 \mathrm{~s}, 72^{\circ} \mathrm{C}$ for $1 \mathrm{~min}$, and $72{ }^{\circ} \mathrm{C}$ for $10 \mathrm{~min}$; for Vipr1/Vipr2, $94{ }^{\circ} \mathrm{C}$ for $10 \mathrm{~min}, 35$ cycles of $94^{\circ} \mathrm{C}$ for $45 \mathrm{~s}, 55^{\circ} \mathrm{C}$ for $45 \mathrm{~s}, 72{ }^{\circ} \mathrm{C}$ for $90 \mathrm{~s}$, and $72{ }^{\circ} \mathrm{C}$ for $10 \mathrm{~min}$. Finally, PCR products and molecular markers were fractionated on $2 \%$ agarose gels and visualized by staining with ethidium bromide. Densitometry was performed, and the results were expressed as arbitrary units normalized to Gapdh expression.

Real-time RT-PCR assays for Vip mRNA expression were performed in the same conditions as RT-PCR. Briefly, for a final volume of $25 \mu \mathrm{l}, 2 \mu \mathrm{l}$ cDNA, $0.20 \mathrm{mM}$ dNTPs, $0.25 \mu \mathrm{M}$ specific primers, $3 \mathrm{mM} \mathrm{MgCl} 2,2 \mathrm{U}$ Taq DNA polymerase, and 1:30000 dilution of SYBR Green were added to the
Table 2 Primer sequences.

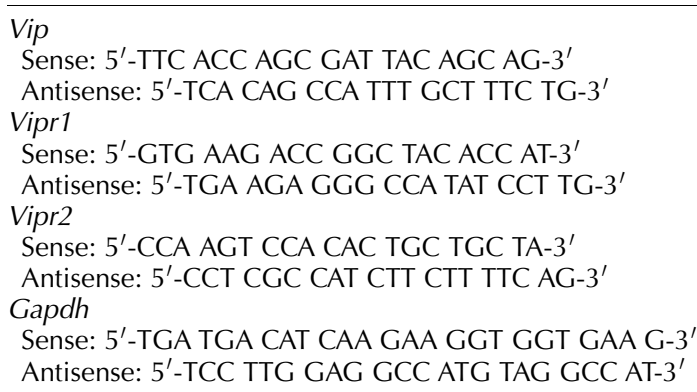

reaction mix. Real-time PCR reactions were performed in a DNA Engine Opticon Real-Time PCR Detection System (Bio-Rad, Price, CA, USA). PCR products were quantified in the Opticon software and normalized to endogenous Gapdh. Each assay included a DNA minus control and a standard curve performed with serial dilutions of control cDNA. All samples were run in duplicate, and the experiment was repeated three times with independently isolated RNA.

\section{Statistical analysis}

Statistical significance of differences was determined by the two-tailed $t$-test for independent populations. When multiple comparisons were necessary, the Student-Newman-Keuls test was used after ANOVA. Differences between groups were considered significant at $P<0.05$.

\section{Declaration of interest}

The authors declare that there is no conflict of interest that could be perceived as prejudicing the impartiality of the research reported.

\section{Funding}

This work was supported by grants PICT 2165 from ANPCyT, PIP 5638 from CONICET, and UBACYT X172 from University of Buenos Aires, Argentina.

\section{Acknowledgements}

We are grateful to Dr Roberto Meiss from Academia Nacional de Medicina for histological studies, presented in Fig. 2.

\section{References}

Abraham GE, Swerdloff R, Tulchinaky D \& Odell WD 1971 Radioimmunoassay of plasma progesterone. Journal of Clinical Endocrinology and Metabolism 32 619-624.

Aisemberg J, Vercelli C, Billi S, Ribeiro ML, Ogando D, Meiss R, McCann SM, Rettori V \& Franchi AM 2007 Nitric oxide mediates prostaglandins' deleterious effect on lipopolysaccharide-triggered murine fetal resorption. PNAS 104 7534-7539.

Aluvihare V, Kallikourdis M \& Betz A 2004 Regulatory T cells mediate maternal tolerance to the fetus. Nature Immunology 3 266-271. 
Ancelin M, Buteau-Lozano H, Meduri G, Osborne-Pellegrin M, Sordello S, Plouet J \& Perrot-Applanat M 2002 A dynamic shift of VEGF isoforms with a transient and selective progesterone-induced expression of VEGF189 regulates angiogenesis and vascular permeability in human uterus. PNAS 99 6023-6028.

Anderson MS \& Bluestone JA 2005 The NOD mouse: a model of immune dysregulation. Annual Review of Immunology 23 447-485.

Burke S, Dong H, Hazan AD \& Croy BA 2007 Aberrant endometrial features of pregnancy in diabetic NOD mice. Diabetes $\mathbf{5 6}$ 1-8.

Chaouat G, Menu E, Clark DA, Dy M, Minkowski M \& Wegmann TG 1990 Control of fetal survival in $\mathrm{CBA} \times \mathrm{DBA} / 2$ mice by lymphokine therapy. Journal of Reproduction and Fertility 89 447-458.

Chiu L, Nishimura M, Ishi Y, Nieda M, Maeshima M, Takedani $Y$, Tadokoro K \& Juji T 1996 Enhancement of the expression of progesterone receptor on progesterone-treated lymphocytes after immunotherapy in unexplained recurrent spontaneous abortion. American Journal of Reproductive Immunology 35 552-557.

Clark KE, Mills EG, Stys SJ \& Seeds AE 1981 Effects of vasoactive polypeptides on the uterine vasculature. American Journal of Obstetrics and Gynecology 139 182-188.

Cutolo M 2000 Sex hormone adjuvant therapy in rheumatoid arthritis. Rheumatic Diseases Clinics of North America 26 881-895.

Ekström J, Mansson B \& Tobin G 1983 Vasoactive intestinal peptide evokes secretion of fluid and protein from rat salivary glands and the development of supersensitivity. Acta Physiologica Scandinavica 119 169-175.

Elson J \& Jurkovic D 2004 Biochemistry in diagnosis and management of abnormal early pregnancy. Current Opinion in Obstetrics \& Gynecology $16339-344$.

Formby B, Schmid-Formby F, Jovanovic L \& Peterson CM 1987 The offspring of the female diabetic "nonobese diabetic" (NOD) mouse are large for gestational age and have elevated pancreatic insulin content: a new animal model of human diabetic pregnancy. Proceedings of the Society for Experimental Biology and Medicine 184 291-294.

Fraccaroli L, Alfieri J, Larocca L, Calafat M, Roca V, Lombardi E, Ramhorst R \& Perez Leiros C 2009 VIP modulates the pro-inflammatory maternal response, inducing tolerance to trophoblast cells. British Journal of Pharmacology 156 116-126.

Gonzalez Rey E \& Delgado M 2007 Vasoactive intestinal peptide and regulatory T-cell induction: a new mechanism and therapeutic potencial for immune homeostasis. Trends in Molecular Medicine $\mathbf{1 3}$ 242-251.

Gressens P, Hill JM, Paindaveine B, Gozes I, Fridkin M \& Brenneman DE 1994 Severe microcephaly induced by blockade of vasoactive intestinal peptide function in the neuroepithelium of the mouse. Journal of Clinical Investigation 94 2020-2027.

Gressens P, Paindaveine B, Hill JM, Evrard P \& Brenneman DE 1998 Vasoactive intestinal peptide shortens both $\mathrm{G} 1$ and $\mathrm{S}$ phases of neural cell cycle in whole postimplantation cultured mouse embryos. European Journal of Neuroscience 10 1734-1742.

Halonen M, Lohman IC, Stern DA, Spangenberg A, Anderson D, Mobley S, Ciano K, Peck M \& Wright AL 2009 Th1/Th2 patterns and balance in cytokine production in the parents and infants of a large birth cohort. Journal of Immunology 182 3285-3293.

Hanzlikova J, Ulcova-Gallova Z, Malkusova I, Sefrna F \& Panzner P 2009 $\mathrm{TH} 1-\mathrm{TH} 2$ response and the atopy risk in patients with reproduction failure. American Journal of Reproductive Immunology 61 213-220.

Inoue Y, Kaku K, Kaneko T, Yanahara N \& Kanno T 1985 Vasoactive intestinal peptide binding to specific receptors on rat parotid acinar cells induces amylase secretion accompanied by cyclic adenosine 30-50monophosphate. Endocrinology 116 686-692.

Jovanovic A, Jovanovic S, Tulic I \& Grbovic L 1998 Predominant role for nitric oxide in the relaxation induced by vasoactive intestinal polypeptide in human uterine artery. Molecular Human Reproduction 4 71-76.

Larocca L, Ramhorst R, Roca V, Calafat M, Aisemberg J, Franchi A \& Pérez Leirós C 2008 Neuroimmune-endocrine interactions during early pregnancy in an autoimmune context: focus on macrophage activation. Neuroimmunomodulation 15 84-90.

Leceta J, Gomariz RP, Martinez C, Carrión M, Arranz A \& Juarranz Y 2007 Vasoactive intestinal peptide regulates Th17 function in autoimmune inflammation. Neuroimmunomodulation 14 134-138.
Li W, Li B, Fan W, Geng L, Li X, Li L, Huang Z \& Li S 2009 CTLA4Ig gene transfer alleviates abortion in mice by expanding $\mathrm{CD} 4{ }^{+} \mathrm{CD} 25^{+}$ regulatory $\mathrm{T}$ cells and inducing indoleamine 2,3-dioxygenase. Journal of Reproductive Immunology 80 1-11.

Lin $\mathbf{Y}, \mathbf{X u} \mathbf{L}$, Jin $\mathbf{H}$, Zhong $\mathbf{Y}$, Di J \& Lin QD 2008 CXCL12 enhances exogenous $\mathrm{CD} 4(+) \mathrm{CD} 25(+) \mathrm{T}$ cell migration and prevents embryo loss in non-obese diabetic mice. Fertility and Sterility 91 2687-2696

Marzioni D, Fiore G, Giordano A, Nabissi M, Florio P, Verdenelli F, Petraglia F \& Castellucci M 2005 Placental expression of substance P and vasoactive intestinal peptide: evidence for a local effect on hormone release. Journal of Clinical Endocrinology and Metabolism 90 2378-2383.

Metcalfe SM, Watson TJ, Shurey S, Adams E \& Green CJ 2005 Leukemia inhibitory factor is linked to regulatory transplantation tolerance. Transplantation 79 726-730.

Moriyama I \& Sugawa T 1972 Progesterone facilitates implantation of xenogeneic cultured cells in hamster uterus. Nature: New Biology 236 $150-152$.

Nelson JL \& Ostensen M 1997 Pregnancy and rheumatoid arthritis. Rheumatic Diseases Clinics of North America 23 195-212.

Ogando DG, Paz D, Cella M \& Franchi AM 2003 The fundamental role of increased production of nitric oxide in lipopolysaccharide-induced embryonic resorption in mice. Reproduction 125 95-110.

Olsen NJ \& Kovacs WJ 2002 Hormones, pregnancy, and rheumatoid arthritis. Journal of Gender-Specific Medicine 5 28-37.

Ottesen B, Ulrichsen H, Fahrenkrug J, Larsen JJ, Wagner G, Schierup L \& Sondergaard F 1982 Vasoactive intestinal polypeptide and the female genital tract: relationship to reproductive phase and delivery. American Journal of Obstetrics and Gynecology 143 414-420.

Piccinni MP, Beloni L, Livi C, Maggi E, Scarselli G \& Romagnani S 1998 Defective production of both, leukemia inhibitor factor and type 2 T-helper cytokines by decidual $\mathrm{T}$ cells in unexplained recurrent abortions. Nature Medicine 4 1020-1024.

Piccirillo CA, Tritt M, Sgouroudis E, Albanese A, Pyzik M \& Hay V 2005 Control of type 1 autoimmune diabetes by naturally occurring $\mathrm{CD} 4{ }^{+} \mathrm{CD} 25^{+}$regulatory $\mathrm{T}$ lymphocytes in neonatal NOD mice. Annals of the New York Academy of Sciences 1051 72-87.

Pop SM, Wong CP, Culton DA, Clarke SH \& Tisch R 2005 Single cell analysis shows decreasing FoxP3 and TGFbeta1 coexpressing $\mathrm{CD} 4{ }^{+} \mathrm{CD} 25^{+}$regulatory $\mathrm{T}$ cells during autoimmune diabetes. Journal of Experimental Medicine 201 1333-1346.

Raghupathy $\mathbf{R} 1997$ Th1-type immunity is incompatible with successful pregnancy. Immunology Today 18 478-482.

Rangon CM, Dicou E, Goursaud S, Mounien L, Jégou S, Janet T, Muller JM, Lelièvre V \& Gressens P 2006 Mechanisms of VIP-induced neuroprotection against neonatal excitotoxicity. Annals of the New York Academy of Sciences 1070 512-517.

Roca V, Rosignoli F, Calafat M \& Pérez Leirós C 2004 Lack of nitric oxidemediated regulation of amylase secretion stimulated by VIP in parotid glands of NOD mice. International Journal of Immunopharmacology $\mathbf{4}$ 1837-1844.

Roca V, Larocca L, Calafat M, Aisemberg J, Meiss R, Franchi A \& Perez Leiros C 2006 Reduced nitric oxide synthase and cyclooxygenase activity in the uterus of non-obese diabetic mice. Reproduction 132 931-938.

Rosignoli F \& Perez Leiros C 2002 Nitric oxide synthase I and VIP activated signaling are affected in salivary glands of NOD mice. Journal of Neuroimmunology 130 109-116.

Rosignoli F, Roca V, Meiss R, Pregi N \& Pérez Leirós C 2004 Inhibition of calcium-calmodulin kinase restores nitric oxide production and signaling in submandibular glands of a mouse model of salivary dysfunction. British Journal of Pharmacology 143 1058-1065.

Rosignoli F, Roca V, Meiss R, Leceta J, Gomariz RP \& Perez Leiros C 2005 Defective signalling in salivary glands precedes the autoimmune response in the non-obese diabetic mouse model of sialadenitis. Clinical and Experimental Immunology 142 411-418.

Rosignoli F, Torroba M, Juarranz Y, Garcia-Gomez M, Martinez C, Gomariz R, Perez Leiros C \& Leceta J 2006 VIP and tolerance induction in autoimmunity. Annals of the New York Academy of Sciences $\mathbf{1 0 7 0}$ 525-530. 
Rugeles MT \& Shearer GM 2004 Alloantigen recognition in utero: dual advantage for the fetus? Trends in Immunology 25 348-352.

Saito S, Shima T, Nakashima A, Shiozaki A, Ito M \& Sasaki Y 2007 What is the role of regulatory $\mathrm{T}$ cells in the success of implantation and early pregnancy? Journal of Assisted Reproduction and Genetics 24 379-386.

Siamopoulou-Mavridou A, Manoussakis MN, Mavridis AK \& Moutsopoulos HM 1988 Outcome of pregnancy in patients with autoimmune rheumatic disease before the disease onset. Annals of the Rheumatic Diseases 47 982-987.

Spong CY, Lee SJ, McCune SK, Gibney G, Abebe DT, Alvero R, Brenneman DE \& Hill JM 1999 Maternal regulation of embryonic growth: the role of vasoactive intestinal peptide. Endocrinology $\mathbf{1 4 0}$ 917-924.

Szekeres-Bartho J 2002 Immunological relationship between the mother and the foetus. International Reviews of Immunology 21 471-495.

Taiym S, Haghighat N \& Al-Hashimi I 2004 A comparison of the hormone levels in patients with Sjogren's syndrome and healthy controls. Oral Surgery, Oral Medicine, Oral Pathology, Oral Radiology, and Endodontics 97 579-583.
Waldorf KM \& Nelson JL 2008 Autoimmune disease during pregnancy and the microchimerism legacy of pregnancy. Immunological Investigations 37 631-644.

Zenclussen AC, Gerlof K, Zenclussen ML, Sollwedel A, Bertoja AZ, Ritter T, Kotsch K, Leber J \& Volk HD 2005 Abnormal T-cell reactivity against paternal antigens in spontaneous abortion: adoptive transfer of pregnancy induced $\mathrm{CD} 4{ }^{+} \mathrm{CD} 25^{+} \mathrm{T}$ regulatory cells prevents fetal rejection in a murine abortion model. American Journal of Pathology 166 811-822.

Zenclussen AC, Gerlof K, Zenclussen ML, Ritschel S, Zambon Bertoja A, Fest S, Hontsu S, Ueha S, Matsushima K, Leber J et al. 2006 Regulatory T cells induce a privileged tolerant microenvironment at the fetal-maternal interface. European Journal of Immunology 36 82-94.

Received 28 April 2009

First decision 2 June 2009

Revised manuscript received 7 July 2009

Accepted 24 July 2009 